to be a more realistic figure, and in an investigation of 184 unselected patients with essential hypertension found 14 patients $(7 \cdot 6 \%)$ who had raised aldosterone secretion and suppressed plasma renin activity. ${ }^{19}$ An adrenocortical adenoma was found at operation, and the hypertension remitted after its removal. Conn's assertion has been questioned by many clinical investigators, some of whom ${ }^{20-22}$ found no evidence for the existence of this entity, and some of whom have reported isolated examples. ${ }^{23} 24$

The clinical picture of these hypertensive syndromes with raised aldosterone secretion is further complicated by the existence of patients with hypertension, hypokalaemic alkalosis, and suppressed plasma renin activity in whom adrenalectomy is not curative, ${ }^{25}$ and who failed to respond to treatment with the aldosterone-antagonist spironolactone. ${ }^{26}$

Another variant is " pituitary-dependent aldosteronism." This is characterized by hypertension, hypokalaemic alkalosis, and an inherited enzyme defect leading to congenital adrenal hyperplasia with excessive aldosterone production. Cortisol production is defective, and the feed-back mechanism causes excess secretion of corticotrophin by the pituitary gland. Suppression of release of corticotrophin by the administration of dexamethasone is curative.

Hence aldosterone may be implicated in various hypertensive syndromes in two ways. In some of these syndromes plasma angiotensin-renin activity is high, resulting in stimulation of aldosterone secretion. In others, aldosterone secretion is stimulated from other sources, and renin secretion is suppressed by the expanded circulating volume. This distinction offers a means of diagnosis. Differentiation of these syndromes from essential hypertension is important, since they afford an opportunity for rational treatment by aldosterone antagonists or surgery, whereas management of essential hypertension remains empirical in the absence of knowledge of its cause.

\section{Mythology of Suicide}

People admitted to hospital after deliberate acts of selfdamage often deny suicidal intention. They offer a variety of explanations, most commonly that they wanted only a good long sleep or to frighten another person. Again, some of those who took an overdose of a narcotic with more or less serious risk to their lives deny having done so intentionally, and some insist that they took only the prescribed dose.

These denial reactions were the subject of a recent study by R. C. B. Aitken and A. T. Proudfoot. ${ }^{1}$ Out of 994 cascs admitted to the Regional Poisoning Treatment Centre at the Royal Infirmary, Edinburgh, 66 denied the act of selfpoisoning, some gave a partial denial - that is, they admitted having taken some drug but much less than the amount indicated by clinical and biochemical evidence. Others completely denied having ingested a drug; or they denied having taken more than the therapeutic dose, though they accepted

1 Aitkın, R. C. B., and Proudfoot, A. T., Postgraduate Medical fournal, 1969, 45, 612.

2 Richards, R., British Medical fournal, 1934, 1, 331.

3 Jansson, B., Acta Psychiatrica et Neurologica Scandinavia, 1962, 38, 183.

4 Long, R. H., Postgraduate Medicine, 1960, 28, A56.

5 Litman, R. E., Curphey, T., Shneidman, E. S., Farberow, N. L., and Tabachnik, N., fournal of the American Medical Association, 1963, 184, 924. that they were poisoned and assumed that they must have taken the drug automatically without intention.

Some doctors, coroners, and members of the general public have accepted this explanation ever since narcotics came to be used increasingly for suicidal acts. In $1934 \mathrm{R}$. Richards, ${ }^{2}$ an expert in forensic medicine, proposed the term "automatism" for this kind of self-poisoning and briefly described three such cases. These patients, he assumed, had continued to ingest tablets because "the memory is so affected by the drug that the patient does not realize that he has already satisfied the need, and automatically repeats the dose at intervals." Only two patients among the large Edinburgh sample explained their condition in this way. However, B. Jansson ${ }^{3}$ reported that no less than one in four of almost 500 patients admitted to a hospital at Göteborg, Sweden, had attributed their poisoning to "automatism." They did not differ in the incidence of typical suicidal attempts in their past history and during a follow-up period of one year from patients who admitted having tried to poison themselves.

Both the Edinburgh patients claiming "automatism" had made a suicidal attempt previously and their histories had much in common with those of the others who denied the act of self-poisoning. Aitken and Proudfoot conclude that there is insufficient evidence for "barbiturate automatism" as a clinical entity and that the failure of these patients to remember the ingestion of more than the therapeutic dose is the result of psychogenic defence mechanisms causing amnesia. Following previous workers, ${ }^{45}$ they dismiss "barbiturate automatism" as a myth. It is doubtful, however, whether their interpretation applies to all cases claiming "automatism," though some who offer this explanation know it to be untrue. Patients' statements about their intentions and actions resulting in self-poisoning and other acts of self-damage are notoriously unreliable, and often they later admit that they had concealed or distorted the truth. Automatism seems to be a respectable version of accidental selfpoisoning and may be a more fashionable explanation in some places than in others. This is a more plausible hypothesis for the causes of the discrepancy between its reported high incidence in Sweden and its rarity in Scotland than the assumption of different liability to psychogenic amnesia. There are fashions not only in the methods of suicidal acts but also in the modes of their denial.

\section{Tubal Ligation in Population Control}

Millions sleep on the streets of overcrowded cities, and every month another million is added to the relentless increase of population. This is India's problem, demanding urgent solution, and no one remedy can possibly effect a cure. But the problem is similar in varying extent in all underdeveloped countries, and is present even within our affluent society, which can tolerate poverty and degradation in over-crowded, substandard, and condemned accommodation.

In this context, a relatively small study of family planning techniques by personal interviews with only 146 women in two Indian village areas may seem too trivial to warrant 
attention. This would be a mistake, for the results ${ }^{1}$ emphasize points of practical importance applicable to India but also to a wider world.

The hospital records were studied of 200 women on whom tubal ligation had been performed up to nine years previously. An experienced social worker interviewed 146 after a houseto-house search of the villages concerned. Operation had been performed in the puerperium in 133, at Caesarean section in 8 , and intrapartum in 5 . The women and their husbands were better educated than the general population of the area. Moreover, both were more literate (husbands particularly so) than those couples who relied on the intrauterine device. In spite of this $68 \%$ had either never heard of birth control or had never used it prior to operation.

An important finding was that before operation 89 of the women consulted 163 friends who had previously had tubal ligation. All advised in its favour, and of the 146 interviewed $98 \%$ advised others to have the same operation. Average age at operation was 30 , though tubal ligation was performed on 15 women in the 20-24-year range and on 3 aged 40-44. The average duration of marriage prior to operation was 13 years and the average number of children was 5, though many women stated they would have requested operation earlier had they known about it. Most preferred to have a son before sterilization.

Similar results have been reported from Puerto Rico, ${ }^{2}$ where $94 \%$ of 519 women expressed satisfaction after operation, and from Pakistan. ${ }^{3}$ In Japan ${ }^{4}$ the number of sterilizations increased from fewer than 6,000 in 1959 to over 44,000 by 1966 , and in Britain $4 \%$ of women admitted to gynaecological wards in 1966 had tubal ligations. ${ }^{5}$

When dealing with the millions of India or Pakistan the logistics of sterilization are formidable. Its contribution will depend on its acceptability and the facilities available for its performance. Male sterilization is quicker, less traumatic, and does not require admission to hospital, but unless suspicions are dispelled and acceptability improved its potential will not be realized. Laparoscopic sterilization as advocated by P. C. Steptoe $^{6}$ would be the nearest comparable technique in women, but it requires delicate and expensive equipment, considerable skill, and admission to hospital. Puerperal sterilization, which was the method most widely used in the series reviewed, has most to offer. The patient can be discharged within a week of delivery and operation.

Restoration of fertility can never be promised, and for this reason tubal ligation should be regarded as permanent and should not be performed if either partner is undecided about further pregnancy. Selection of patients is therefore most important. The implications of the operation should be explained to both husband and wife, and their written consent is essential. Finally, as reported from Oxford, ${ }^{78}$ tubal ligation is contraindicated in a sizeable group of women with uterine disease, for whom hysterectomy is a better procedure. With

1 Lippitt, T., Ranganathan, K. V., and Hulka, J. F., American fournal of Obstetrics and Gynecology, 1969, 105, 434.

2 Paniagua, M. E., Tayback, M., Janer, J. L., and Vázquez, J. L., American fournal of Obstetrics and Gynecology, 1964, 90, 421 .

3 Roberts, Beryl, J., et al., fournal of the Pakistan Academy of Rural Development, 1964, 4, 3 .

4 Koya, Y., Eugenics Quarterly, 1961, 8, 135. - Peel, J., Fournal of Obstetrics and Gyizaecology of the British Commonwealth,
1969, 76, 1042.

6 Steptoe, P. C., Fournal of Obstetrics and Gynaecology of the British Commonwealth, 1969, 76, 1043.

7 Stallworthy, J. A., fournal of Obstetrics and Gynaecology of the British Commonwealth, 1969, 76, 1042.

8 Williams, E. A., Lancet, 1969, 1, 1093. these reservations, tubal ligation is an effective method of family planning which deserves wider recognition, both in Britain and abroad.

\section{Surgical Contrasts}

One of the enigmas facing the planners in this spring of Green Papers must be the relationship between the demand for medical services and the need for them. Many people seem to clamour for more than can be good for them; a modest minority are thought to receive too little for their health. But that striking a balance between demand and need is not a problem peculiar to the welfare State is evident from a recent article in the U.S.A. Dr. John P. Bunker ${ }^{1}$ reports that there are twice as many surgeons in proportion to population in the U.S.A. as in England and Wales and that, likewise in proportion to population, they perform twice as many operations as their confrères over here. No wonder the New England Fournal of Medicine asks, "What puts the surge in surgery?"

The question that naturally comes to mind is whether Americans are getting too much and Britons too little surgery -though the alternatives of whether both are getting too much or too little cannot be altogether excluded. Part of the discrepancy between the two countries can be attributed to a real need for more surgery in the U.S.A. in the treatment of road accidents-a need that is fulfilled-and to the difference must be added a need that goes unfulfilled over here, according to Dr. Bunker. He says "many British physicians believe that there are a large number of patients in need of surgery for cataract, and the long waiting lists for herniorrhaphy and prostatectomy are common gossip." But of course against the hazard of having one of these conditions untreated must be weighed the hazard of the operation itself. The difficulty of balancing these chances with any precision for the individual patient points also to another dilemma: what is this "need" to match against "demand"?

At first sight it might be thought that operations which are free at the time under our Health Service would be relatively more numerous than the often expensive procedures under American private enterprise, with or without insurance cover. But in the organization of medical care over here the place of the general practitioner is in many ways crucial. Certainly those who in moments of despondency think of themselves as little more than a filter are vastly underrating their role. It is the British family doctor's much greater familiarity with his patients than is possible to many American doctors that enables him to assess their real needs more accurately. Patients who can go straight to surgeons, as they do in the U.S.A., will probably get a surgical answer to their worries. As Dr. Bunker puts it, surgeons and nonsurgeons are apt to have very different ideas of indications for surgery. But as well as divergence in the medical organization of the two countries Dr. Bunker sees differences in surgical philosophy. "In keeping with his national character the American surgeon is more aggressive." The British surgeon "is more modest in his expectations, possibly more realistic, but also possibly missing opportunities for surgical cure." It is especially in elective procedures that these different outlooks may show their effects most plainly.

${ }^{1}$ Bunker, J. P., New England fournal of Medicine, 1970, 282, 135. 